\title{
Influence of Curing Time on the Drying Shrinkage of Concretes with Different Binders and Water-to-Binder Ratios
}

\author{
Jun Yang, ${ }^{1}$ Qiang Wang, ${ }^{1}$ and Yuqi Zhou ${ }^{2}$ \\ ${ }^{1}$ Department of Civil Engineering, Tsinghua University, Beijing 100084, China \\ ${ }^{2}$ China Construction First Group Construction and Development Co., Ltd., Beijing 100102, China
}

Correspondence should be addressed to Qiang Wang; w-qiang@tsinghua.edu.cn

Received 21 March 2017; Accepted 26 April 2017; Published 11 May 2017

Academic Editor: Yao Luan

Copyright (C) 2017 Jun Yang et al. This is an open access article distributed under the Creative Commons Attribution License, which permits unrestricted use, distribution, and reproduction in any medium, provided the original work is properly cited.

Plain cement concrete, ground granulated blast furnace slag (GGBS) concrete, and fly ash concrete were designed. Three wet curing periods were employed, which were 2, 5, and 8 days. The drying shrinkage values of the concretes were measured within 1 year after wet curing. The results show that the increasing rate of the drying shrinkage of concrete containing a mineral admixture at late age is higher than that of plain cement concrete regardless of the wet curing time. With the reduction of wet curing time, the increment of total drying shrinkage of concrete decreases with the decrease of the W/B ratio. The negative effects on the drying shrinkage of fly ash concrete due to the reduction of the wet curing time are much more obvious than those of GGBS concrete and plain cement concrete. Superfine ground granulated blast furnace slag (SGGBS) can reduce the drying shrinkage of GGBS concrete and fly ash concrete when the wet curing time is insufficient.

\section{Introduction}

Drying shrinkage of concrete is a phenomenon that is caused by the moisture drying from the pore system of the hardened paste and thus leads to volume shrinkage of the concrete $[1,2]$. While the humidity of the surroundings is less than that of the concrete, the moisture in concrete begins to evaporate and then drying shrinkage of concrete occurs [3,4]. Drying shrinkage of concrete is governed by the cement paste content, while the aggregates do not shrink in general [1]. Drying shrinkage is a major factor in the cracking of concrete, so the strength of concrete is affected by drying shrinkage [24].

There are four prominent physical models proposed to account for the mechanism of drying shrinkage: capillary tension [5-7], loss of interlayer water [8], changes in surface energy [5], and disjoining pressure [9], of which capillary tension and disjoining pressure are widely accepted. Each of these models is applied to various conditions at different levels of relative humidity, and more than one mechanism is involved at different stages in practice $[2,5-10]$. At an early age, drying shrinkage occurs because of a combination effect of grain connection (causing pore formation) and water evaporation (creating menisci), which reaches a mechanical percolation threshold [11]. It should be noted that earlyage drying shrinkage is not an immediate consequence of drying until the capillary water is removed [12], and earlyage drying shrinkage near the drying surface develops much more quickly than that in the center of the concrete element [13]. Early-age drying shrinkage mainly occurs between 1.5 and 4 hours after casting, which indicates that it is related to both the microstructure development and the environmental effect [11]. Capillary tension is a comprehensive explanation of early-age drying shrinkage if the pore diameters are larger than approximately $10 \mathrm{~nm}$ with relative humidity above $40 \%-50 \%$ [14-16]. When the moisture in the capillaries evaporates, the menisci formed lead to a negative pressure difference between the vapor phase and the liquid phase, which means the pressure in the liquid is lower than the atmospheric pressure. As a result, a force imbalance occurs, which leads to the shrinkage of the solid and contraction of the pores [17, 18]. However, the mechanism of long-term drying shrinkage can be well explained by the disjoining pressure. It was found by Beltzung and Wittmann [19] and Maruyama and Sugie [20] that only the disjoining pressure was relevant to the drying shrinkage in a mature paste. 
Disjoining pressure reveals that when the separation distance between pores is small, surface forces, such as van der Waals or electrostatic forces, become remarkable [21]. Due to the water loss from the capillary pores and the gels, water-air menisci form, which subjects the pore walls to considerable stress [22]. Meanwhile, the repulsive forces that exist in the presence of water that resist the van der Waals attraction are diminished by the removal of the water. Consequently, an imbalance between opposing surfaces occurs, resulting in the contraction of the solid body [17].

Fly ash is a by-product of the combustion of pulverized coal in power plants that acts as a pozzolanic material in concrete. Fly ash blended cement can make an improvement in the pore structure of concrete due its pozzolanic and microaggregate effects $[23,24]$. It was confirmed by Papadakis [25] that fly ash had a significant effect on the porosity of concrete that greatly influenced drying shrinkage. Yang et al. [26] found that high volumes of fly ash could reduce drying shrinkage, and the reduction of drying shrinkage increased with increasing fly ash content. The main mechanism of earlyage drying shrinkage reduction of concrete containing fly ash was reported to be the filling effect of fly ash, which can decrease the porosity and connectivity among pores [2326]. In the long-term, the drying shrinkage of the concrete containing fly ash might be more reduced when compared to that at an early age due to the densification of the matrix. The densification is a result of the shape property and pozzolanic and microfilling effects of fly ash, which can prevent internal moisture evaporation and it is more distinct at a later age. Moreover, the higher strength of the concrete due to the replacement of fly ash at a later stage is beneficial to the prevention of compression deformation [27]. The research of Khatib [28] showed that there existed a systematic reduction of the drying shrinkage as the fly ash content increased and the relationship between the drying shrinkage at 56 days and fly ash content was linear. In contrast, Akkaya et al. [29] found that fly ash and ultra-fine fly ash both increased the drying shrinkage, and the reason for this phenomenon was the decrease of the elasticity modulus of the concrete and the differences in pore structure connectivity, which could make moisture escape easier [30, 31]. An early research conducted by Pfeifer [32] demonstrated that the drying shrinkage of fly ash aggregate lightweight concrete was approximately $30 \%$ greater than that of comparable normal-weight concrete. Kayali et al. [33] found that lightweight aggregate concretes made with sintered fly ash aggregates showed a greater longterm drying shrinkage than normal concrete containing no fly ash, and they reported that the higher paste content may account for this finding.

Blast furnace slag is also widely used as a mineral admixture in concrete [34]. It was found that the drying shrinkage of the concrete containing $65 \%$ slag is the lowest when compared to those of the concretes containing a lower percentage of slag [35]. Tazawa et al. [36] reported that the drying shrinkage of concrete containing slag was less than that of pure cement concrete when cured for 28 days. Yuan et al. [37] found that partially replacing cement with slag decreased the drying shrinkage compared to that of pure cement concrete. The reduction of the drying shrinkage was greater at early ages as well as with the increase of the replacement ratio, and the factor that contributes to this was that the slag can keep the water content constant due to its good hydroscopicity and inertness at the early stage [37]. However, Deshpande [38] found that the drying shrinkage of concrete containing slag increased slightly at an early age (30 days), whereas the ultimate drying shrinkage (1 year) was little affected. Hooton et al. [39] concluded that the drying shrinkage of concrete containing slag was approximately the same as that of pure cement concrete regardless of slag content. Wedding et al. [40] reported that slag appeared to increase the drying shrinkage significantly. Garci Juenger and Jennings [41] demonstrated that a higher later stage drying shrinkage of slag blended concrete was due to the higher proportion of mesopore, and it was also found that high surface area and pore volumes (pore sizes 1-40 nm) contributed to high values of total drying shrinkage. Chern and Chan [42] proposed that the drying shrinkage of blast furnace slag concrete was higher than ordinary Portland cement concrete, which was due to the greater volume of paste in blast furnace slag concrete.

The water/binder $(\mathrm{W} / \mathrm{B})$ ratio is another important factor affecting the drying shrinkage of concrete. In general, a high $\mathrm{W} / \mathrm{B}$ ratio increases the drying shrinkage with the tradition explanation that a higher $\mathrm{W} / \mathrm{B}$ ratio leads to a greater volumetric cement paste content and less restraint of deformation [43]. Specifically, if the $\mathrm{W} / \mathrm{B}$ ratio is high, the concrete will be more porous with more connectivity, which means the moisture in the concrete can escape into the atmosphere more easily [44-46]. However, Bissonnette et al. [47] proposed that the W/B ratio, under some conditions or within a given $\mathrm{W} / \mathrm{B}$ ratio range, was not as important as it was often considered to be, and the factors that are dependent on the $\mathrm{W} / \mathrm{B}$ ratio, such as pore-size distribution, total porosity, and elasticity modulus, might have opposite individual effects, which may offset the overall effect of drying shrinkage.

The wet curing time of the concrete before being exposed to the drying environment has an impact on the development of drying shrinkage. In this work, the influence of wet curing time on the drying shrinkage of concrete was experimentally evaluated with different mineral admixtures and $\mathrm{W} / \mathrm{B}$ ratios.

\section{Raw Materials and Test Methods}

Table 1 shows the chemical compositions of the cement, GGBS, and fly ash used in this paper. The specific surface area values of the cement, GGBS, and fly ash were 312, 409, and $354 \mathrm{~m}^{2} / \mathrm{kg}$, respectively. A superfine ground granulated blast furnace slag (SGGBS) was obtained by further grinding the GGBS to a specific surface area of $616 \mathrm{~m}^{2} / \mathrm{kg}$. The fine aggregate was natural river sand with size smaller than $5 \mathrm{~mm}$. The coarse aggregate was crushed limestone with size between 5 and $20 \mathrm{~mm}$. The superplasticizer was a polycarboxylic acid water reducing agent.

The mix proportions of the 8 concretes were listed in Table 2. Two water/binder (W/B) ratios were used: 0.50 and 0.42. The total amounts of binder as well as fine aggregates 
TABLE 1: Chemical compositions of cement, GGBS, and fly ash (\%).

\begin{tabular}{lccccccc}
\hline & $\mathrm{CaO}$ & $\mathrm{SiO}_{2}$ & $\mathrm{Al}_{2} \mathrm{O}_{3}$ & $\mathrm{Fe}_{2} \mathrm{O}_{3}$ & $\mathrm{MgO}$ & $\mathrm{Na}_{2} \mathrm{O}_{\text {eq }}$ & $\begin{array}{c}\text { Loss on } \\
\text { ignition }\end{array}$ \\
\hline Cement 63.59 & 21.86 & 4.25 & 2.66 & 2.19 & 0.55 & 1.75 \\
GGBS & 36.44 & 31.76 & 14.84 & 0.60 & 9.08 & 0.56 & 0 \\
Fly ash & 2.44 & 48.67 & 30.95 & 5.62 & 1.15 & 0.78 & 7.65 \\
\hline
\end{tabular}

Note. $\mathrm{Na}_{2} \mathrm{O}_{\text {eq }}=\mathrm{Na}_{2} \mathrm{O}+0.658 \mathrm{~K}_{2} \mathrm{O}$.

and coarse aggregates are the same. The replacement ratio of mineral admixture is $40 \%$.

Prism specimens measuring $100 \times 100 \times 515 \mathrm{~mm}$ were prepared for the drying shrinkage test. Prism specimens measuring $100 \times 100 \times 300 \mathrm{~mm}$ were prepared for the elastic modulus test. Cube specimens measuring $100 \times 100 \times 100 \mathrm{~mm}$ were prepared for the permeability tests. The specimens were all cast in steel molds and cured under the wet curing condition $\left(20 \pm 1^{\circ} \mathrm{C}\right.$ and a relative humidity of more than $\left.95 \%\right)$ for the first day. After 1 day, the specimens were demolded.

Three curing methods were employed: (a) wet curing for 2 days and then dry curing $\left(20 \pm 1^{\circ} \mathrm{C}\right.$ and a relative humidity between $45 \%$ and $55 \%$ ) for the remaining ages; (b) wet curing for 5 days and then dry curing for the remaining ages; and (c) wet curing for 8 days and then dry curing for the remaining ages. The wet curing period includes the first day when the specimen was in the mold.

The drying shrinkage of the concretes was measured right after the wet curing period. The drying shrinkage values were measured within 360 days' drying. Chloride ion permeability test was carried out according to ASTM C1202, "Standard Test Method for Electrical Indication of Concrete's Ability to Resist Chloride Ion Penetration." The nonevaporable water content values of the paste were obtained as the mass differences between the samples heated at $105^{\circ} \mathrm{C}$ and $1000^{\circ} \mathrm{C}$. These results were normalized by the mass after heating at $105^{\circ} \mathrm{C}$ and corrected for the loss on ignition of unhydrated samples.

\section{Results and Discussion}

3.1. Drying Shrinkage Development. Autogenous shrinkage is defined as the change of the concrete volume without the transfer of moisture to the environment after the initial setting [48]. It is a result of self-desiccation, which is closely related to the chemical reactions (mainly the hydration of the cement) in the concrete. As a result, empty pores are created. If the amount of water is not sufficient to fill these empty pores, considerable shrinkage occurs [48, 49]. Autogenous shrinkage increases with the decrease of the $\mathrm{W} / \mathrm{B}$ ratio. It was reported by Aitcin et al. [50] that the autogenous shrinkage would be very small when the W/B ratio was greater than 0.42 , but it developed rapidly if the $\mathrm{W} / \mathrm{B}$ ratio was lower than 0.42 . Autogenous shrinkage occurs as soon as the hydration begins and develops more quickly when the paste is young (within 24 hours); thus, it must be measured before concrete has aged 24 hours [51-53]. In this work, the W/B ratios were set as 0.42 and 0.5 , and the wet curing time was at least 2 days.

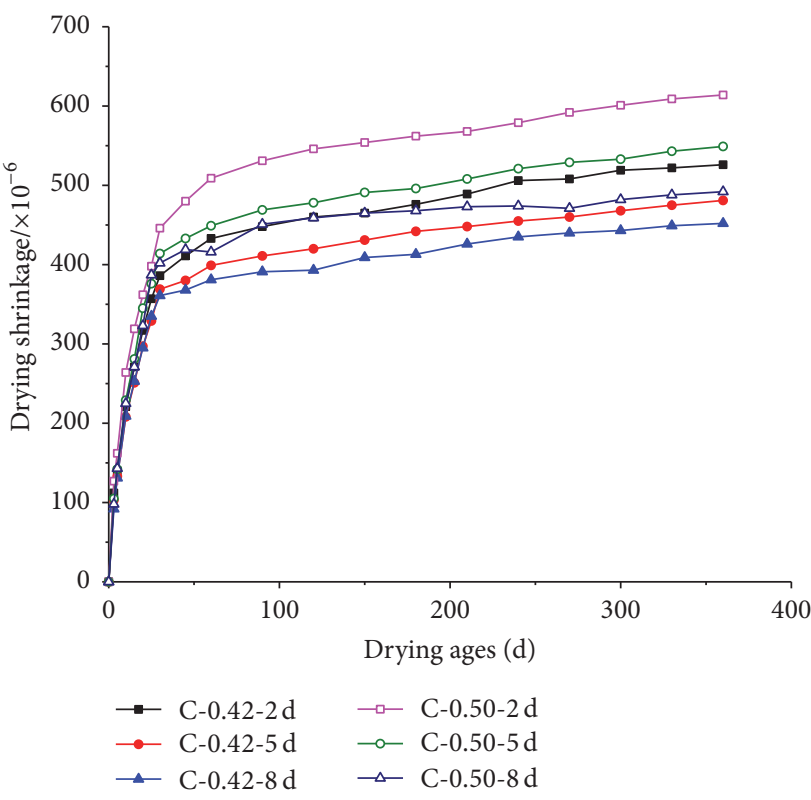

FIGURE 1: Drying shrinkage of plain cement concrete.

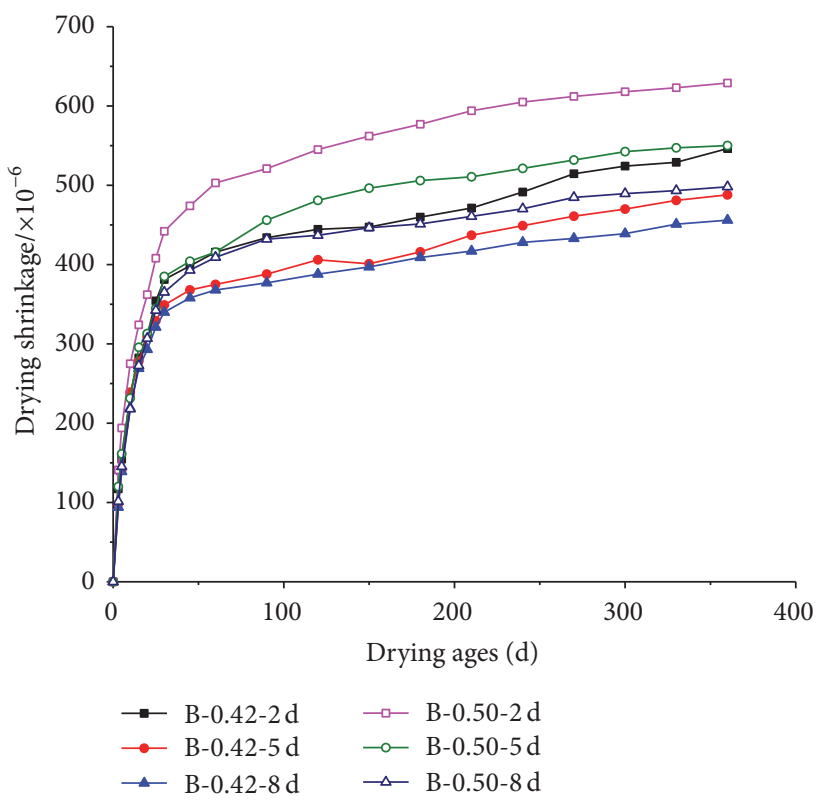

FIGURE 2: Drying shrinkage of GGBS concrete.

Consequently, autogenous shrinkage can be neglected in this work.

Figures 1, 2, and 3 show the drying shrinkage of plain cement concrete, GGBS concrete, and fly ash concrete, respectively, within 1 year after wet curing for 2,5 , and 8 days with $\mathrm{W} / \mathrm{B}$ ratios of 0.42 and 0.50 . The three figures show two common laws: (1) the drying shrinkage values of the concretes decrease with the decrease of the W/B ratio, which is due to the increase of stiffness and compactness of the concretes under the same conditions regardless of the cementing components. This is consistent with the study of Brooks et al. [43-46]. (2) For the same cementing component 
TABLE 2: Mix proportions of the concretes $\left(\mathrm{kg} / \mathrm{m}^{3}\right)$.

\begin{tabular}{|c|c|c|c|c|c|c|c|}
\hline & Cement & GGBS & Fly ash & SGGBS & Coarse aggregates & Fine aggregates & Water \\
\hline C- 0.50 & 360 & 0 & 0 & 0 & 1060 & 800 & 180 \\
\hline B- -0.50 & 216 & 144 & 0 & 0 & 1097 & 763 & 180 \\
\hline F-0.50 & 216 & 0 & 144 & 0 & 1116 & 744 & 180 \\
\hline SB- 0.50 & 216 & 108 & 0 & 36 & 1097 & 763 & 180 \\
\hline SF- 0.50 & 216 & 0 & 108 & 36 & 1116 & 744 & 180 \\
\hline C- 0.42 & 360 & 0 & 0 & 0 & 1077 & 812 & 151.2 \\
\hline B- 0.42 & 216 & 144 & 0 & 0 & 1114 & 774 & 151.2 \\
\hline F- 0.42 & 216 & 0 & 144 & 0 & 1133 & 756 & 151.2 \\
\hline
\end{tabular}

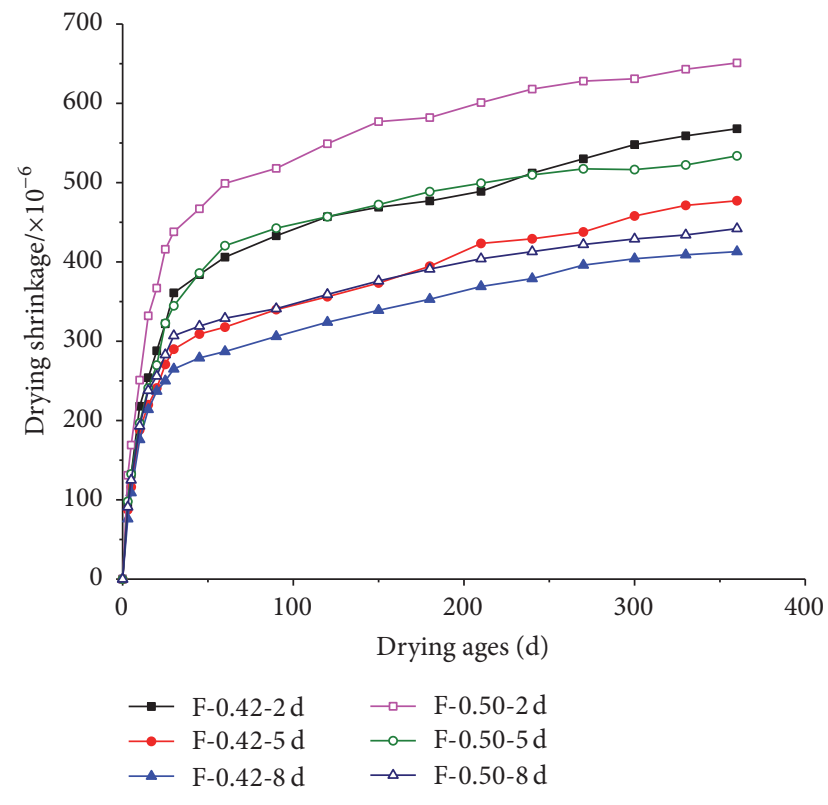

FIGURE 3: Drying shrinkage of fly ash concrete.

with the same $\mathrm{W} / \mathrm{B}$ ratio, the drying shrinkage values of the concretes obviously increase with the decrease of the wet curing time.

However, the three figures also show some different laws: (1) the drying shrinkage values of the three concretes differ from each other due to their different curing conditions. After wet curing for 8 days, the drying shrinkage of GGBS concrete is close to that of plain cement concrete, whereas the drying shrinkage of fly ash concrete is much less than that of the other two concretes. After wet curing for 2 days, drying shrinkage of GGBS concrete is still close to that of the plain cement concrete, whereas the drying shrinkage of the fly ash concrete is obviously larger than that of the other two concretes, which is contrary to that found under the condition of wet curing for 8 days. This indicates that prolonging the wet curing time decreases the drying shrinkage of fly ash concrete much more obviously than that of the GGBS concrete and plain cement concrete. This is mainly due to the low activity of fly ash at an early age. Therefore, more wet curing time is needed to ensure the full hydration of the cement and the activation of the fly ash by the $\mathrm{Ca}(\mathrm{OH})_{2}$ produced. (2) The increasing rates of the drying shrinkage of the three concretes show great differences from each other at the late age. For plain cement concrete, the increasing rate of drying shrinkage is very slow at the late age regardless of the length of wet curing time. However, the drying shrinkage values of GGBS concrete and fly ash concrete increase greatly at the late age after wet curing for 2 days. Comparatively, the increasing rate of drying shrinkage of fly ash concrete was larger at the late age. After wet curing for 5 or 8 days, the increasing rates of drying shrinkage of GGBS concrete and fly ash concrete at the late age are a little slower than those after wet curing for 2 days, and they are still much larger than that of plain cement concrete. Similarly, the increasing rate of drying shrinkage of fly ash concrete is comparatively larger at the late age.

This indicates that the wet curing time has a greater influence on concrete containing mineral admixtures than plain cement concrete. Two reasons may account for it: (1) when wet curing is insufficient (only 2 days), the reaction degrees of GGBS and fly ash are low, which makes their pore structures coarse and the connected porosity increases at late age. Thus, the moisture in concrete transfers quickly and the loss of moisture from the gels increases, leading to an increase of the drying shrinkage at the late age. Comparatively, the reaction degree of fly ash is lower and thus the pore structure pore is coarser at the late age, which results in a greater increase of drying shrinkage. (2) When wet curing for 5 days or 8 days, the reaction degrees of GGBS and fly ash are relatively high at the late age, which decreases the porosity and is a benefit for improving the pore structure at late age. Specifically, the proportion of pores smaller than $10 \mathrm{~nm}$ increases, leading to a high capillary pressure and an increase of the drying shrinkage at the late age [54]. Comparatively, the reaction degree of fly ash at the late age is higher and the pore structure of concrete is finer, which increases the proportion of pores smaller than $10 \mathrm{~nm}$, causing larger drying shrinkage.

3.2. Comparison of Effects on Drying Shrinkage due to the Change of Wet Curing Time. The nonevaporable water $\left(\mathrm{w}_{n}\right)$ content is the amount of water chemically bonded with the hydration products, and it is proportional to the amount of hydration products and is often used to determine the hydration degree of cement. Figure 4 shows the $\mathrm{w}_{n}$ contents of plain cement, composite binder containing GGBS, and fly ash. It is notable that the increasing amplitude of the $\mathrm{w}_{n}$ content of the composite binder is obviously larger than 


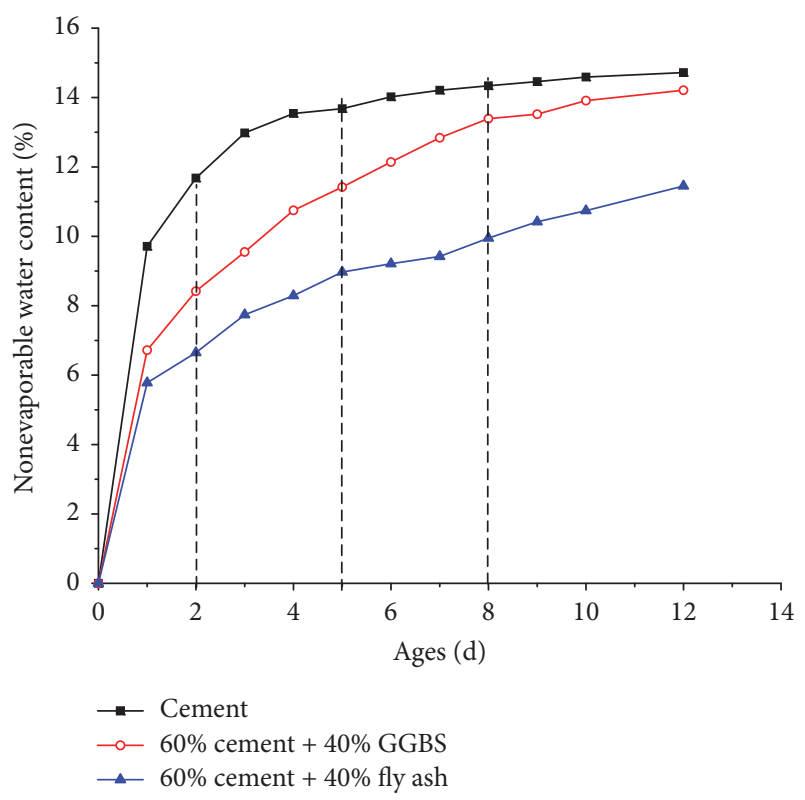

FIGURE 4: Nonevaporable water contents of the hydration products of binders.

that of plain cement when the wet curing time increases from 2 to 5 days as well as from 5 to 8 days, which means the increase of hydration degree of the composite binder is greater than that of plain cement. Thus, it can be inferred that the stiffness and compactness of the concrete containing fly ash or GGBS improve more significantly than those of plain cement concrete when the wet curing time increases from 2 to 5 days as well as from 5 to 8 days. It is worth noting that $\mathrm{w}_{n}$ content of plain cement has reached a high degree after wet curing for 2 days, and its increasing amplitude is very small when the wet curing time increases from 2 to 5 days as well as from 5 to 8 days. Therefore, the wet curing time tends to have a greater influence on the hydration degree and microstructure development of the concrete containing mineral admixture than those of plain cement concrete.

Figure 5 shows the elastic modulus of plain cement concrete, GGBS concrete, and fly ash concrete with a W/B ratio of 0.42 . It can be seen that the changes of the elastic modulus of plain cement concrete and GGBS concrete are not regular with the change of wet curing time, which indicates that the length of wet curing time tends to have a limited influence on their elastic modulus at the ages of 28 and 360 days. For fly ash concrete, its elastic modulus increases as the wet curing time increases at the ages of 28 and 360 days.

The entire elastic modulus of concrete is dependent on both the hardened paste and the aggregates. The length of wet curing time does not affect the elastic modulus of the aggregates, and thus it has less influence on the entire elastic modulus of the concrete than it has on that of the hardened paste. It is believed that the elastic modulus of plain cement paste and paste containing GGBS is reduced to some extent due to the decrease of the wet curing time. However, the entire elastic modulus values of plain cement concrete and GGBS concrete are little affected by wet curing time. Furthermore, the decrease of wet curing time has an obvious influence on

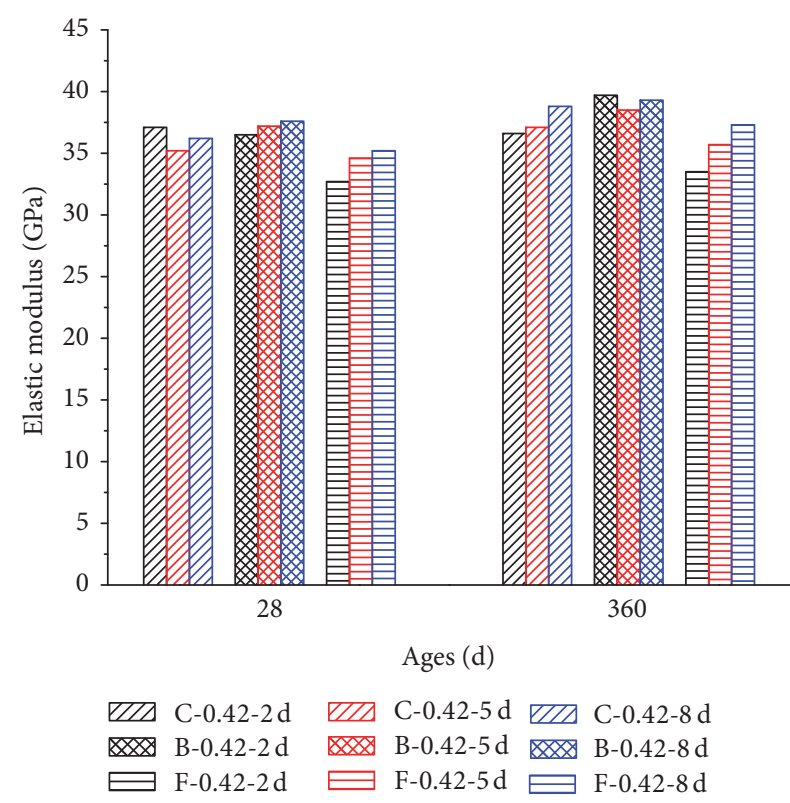

FIgURE 5: Elastic modulus of the concretes with W/B ratio of 0.42 .

the entire elastic modulus of fly ash concrete. This indicates that the elastic modulus of paste containing fly ash decreases much more significantly than that of paste containing GGBS and plain cement due to the reduction of the wet curing time. The trend of the entire elastic modulus of concrete is closely related to that of the stiffness of the concrete. Therefore, it can be concluded that as for the fly ash concrete, the decline of elastic modulus is one of the reasons for the increase of the drying shrinkage by decreasing the wet curing time. However, for the cement concrete and GGBS concrete, the influence on elastic modulus can be neglected.

Figures 6, 7, and 8 show the charge passed and chloride permeability grade of plain cement concrete, GGBS concrete, and fly ash concrete, respectively, with a W/B ratio of 0.42 . Overall, the chloride permeability grades of the concrete with mineral admixtures are lower than those of plain cement concrete at the ages of 28 and 360 days.

For plain cement concrete, the chloride permeability values of concretes with different wet curing periods are in the same grade (moderate level) at the age of 28 days. This indicates that the decrease of wet curing time does not affect the chloride permeability grade of plain cement concrete at 28 days. In the case of wet curing for 8 days, the permeability of plain cement concrete falls into the "low" grade at the age of 360 days, whereas the permeability of plain cement concrete after wet curing for 5 or 2 days is still in the "moderate" grade at 360 days. This indicates that shortening the wet curing time from 8 to 5 days can improve the chloride permeability grade of plain cement concrete at 360 days, while shortening the wet curing time from 5 to 2 days cannot.

For GGBS concrete, the chloride permeability values of concretes with different wet curing periods are in the same grade (low level) at the age of 28 days. This indicates that the decrease of wet curing time does not affect the chloride permeability grade of GGBS concrete at 28 days, which is 


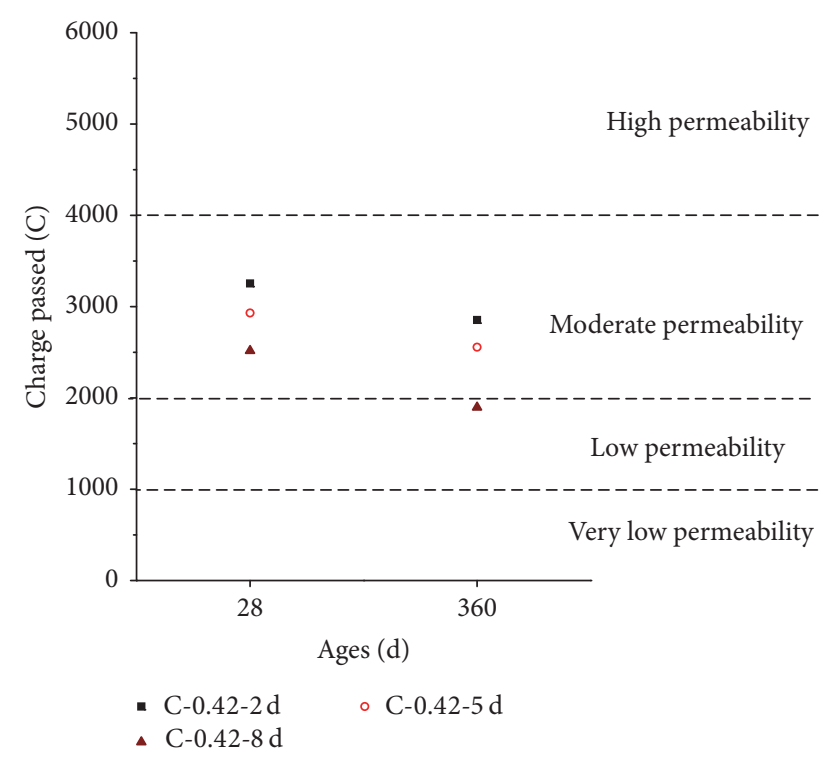

FIgURE 6: Chloride permeability of plain cement concrete.

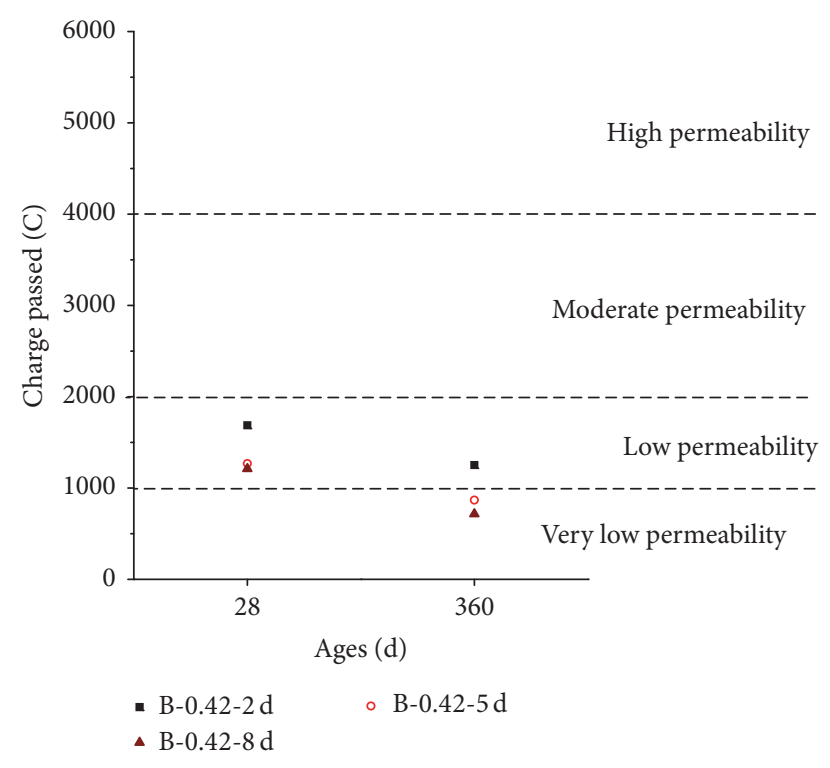

FIGURE 7: Chloride permeability of GGBS concrete.

similar to the case of plain cement concrete. In the case of wet curing for 8 or 5 days, the permeability of GGBS concrete falls in the "very low" grade at the age of 360 days, whereas the permeability of GGBS concrete after wet curing for 2 days is still in the "low" grade at 360 days. This indicates that shortening the wet curing time from 5 to 2 days can improve chloride permeability grade of GGBS concrete at 360 days, while shortening the wet curing time from 8 to 5 days cannot.

For fly ash concrete, the chloride permeability values of concretes after wet curing for 8 and 5 days are in the same grade (low level) at the age of 28 days, whereas those after wet curing for 2 days are in "moderate" grade. This indicates that shortening the wet curing time from 5 to 2 days can improve the chloride permeability grade of fly ash concrete at 28 days, while shortening the wet curing time from 8 to 5 days cannot.

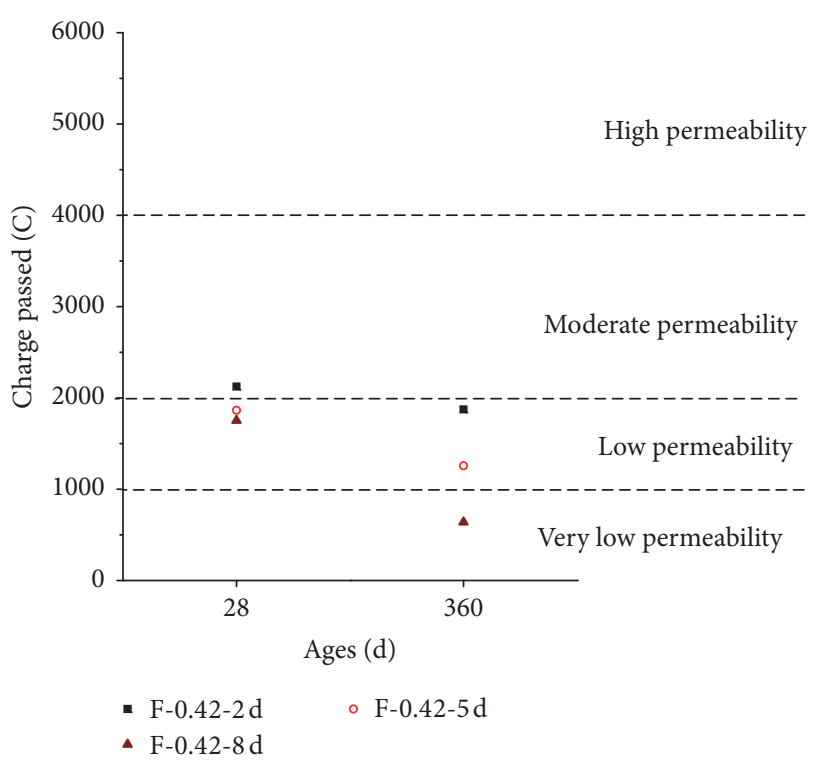

FIGURE 8: Chloride permeability of fly ash concrete.

In the case of wet curing for 8 days, the permeability of fly ash concrete falls in the "very low" grade at the age of 360 days, whereas the permeability of fly ash concrete after wet curing for 5 or 2 days is still in the "low" grade at 360 days. This indicates that shortening the wet curing time from 8 to 5 days can improve chloride permeability grade of fly ash concrete at 360 days, while shortening the wet curing time from 5 days to 2 days cannot.

To study the influence of the reduction of the wet curing time on the drying shrinkage of concretes at different ages, the drying shrinkage of concrete at 30 days is defined as early drying shrinkage and the drying shrinkage of concrete at 360 days is defined as total drying shrinkage. Figures 9 and 10 show the increments of early and total drying shrinkage of the different concretes when the wet curing time decreased from 8 to 5 days and from 5 to 2 days, respectively.

Figures 9 and 10 show two common laws as follows: (1) as the wet curing time is reduced, the increments of total drying shrinkage of the three concretes are obvious and decrease with the decrease of the W/B ratio. (2) The increments of early and total drying shrinkage of fly ash concrete are much larger than those of the GGBS concrete and plain cement concrete with the reduction of the wet curing time, which indicates that the negative effects due to the reduction of the wet curing time on the drying shrinkage of fly ash concrete are much more obvious than those of GGBS concrete and plain cement concrete. This is mainly due to the low activity of the fly ash. The hydration degree of cement and the reaction degree of fly ash are relatively lower and the pore structure is coarser when the wet curing time is reduced. As a result, the moisture in the concrete transfers more easily and thus the increment of the drying shrinkage of fly ash concrete is larger. Furthermore, it can be seen from the elastic modulus results that the influence due to the reduction of wet curing time on the elastic modulus of plain cement concrete and GGBS concrete is limited. However, the reduction of wet curing time 


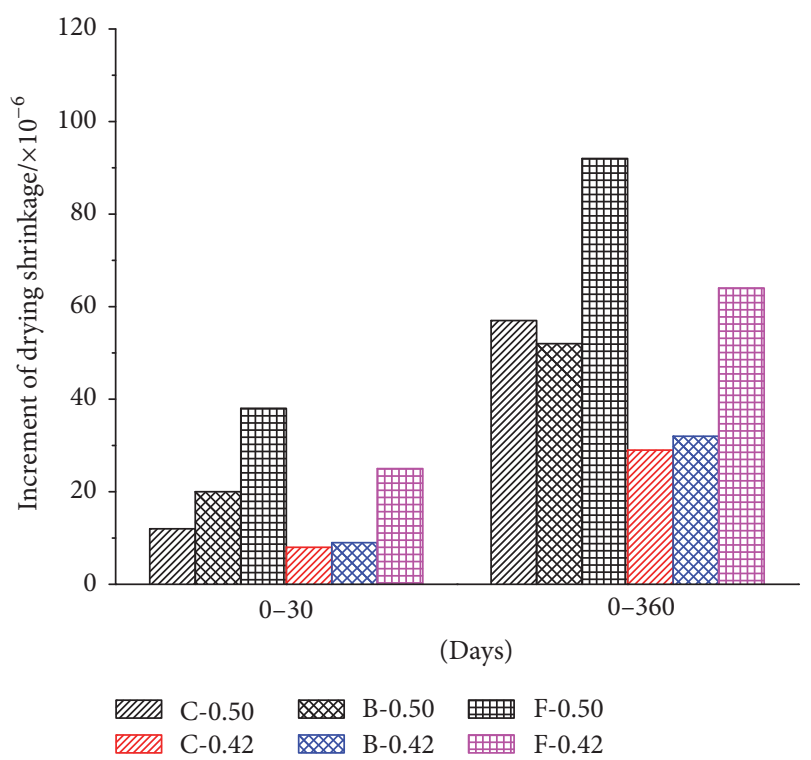

FIGURE 9: The increments of drying shrinkage of concretes when the wet curing time decreases from 8 days to 5 days.

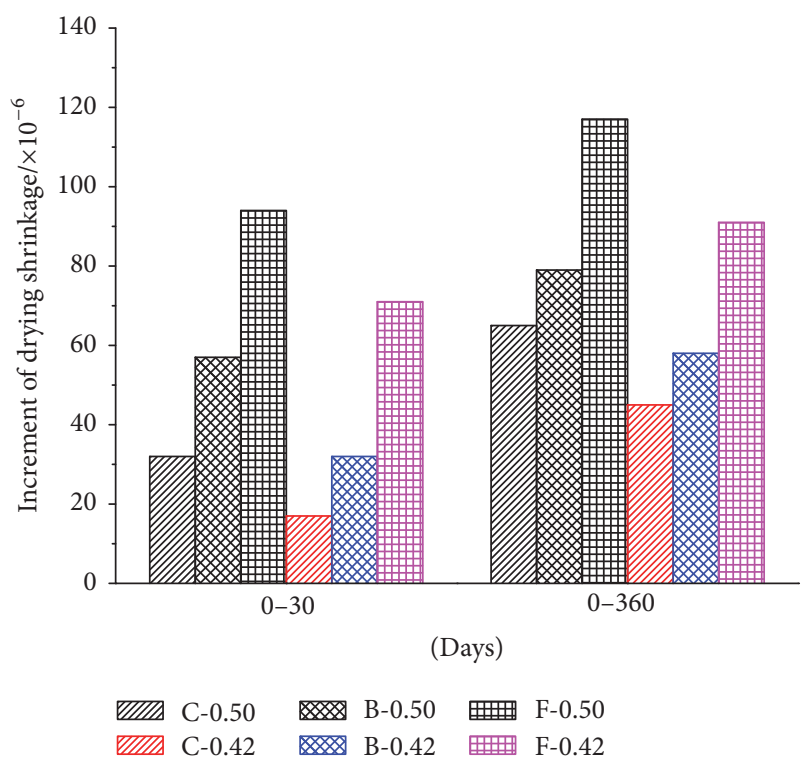

FIGURE 10: The increments of drying shrinkage of concretes when the wet curing time decreases from 5 days to 2 days.

decreases the elastic modulus of fly ash concrete significantly and thus leads to a large increment of drying shrinkage.

However, there are also some differences between the two figures: (1) the increments of early drying shrinkage of GGBS concrete and plain cement concrete are very small (only approximately $10 \mu \varepsilon$ ), which can almost be neglected when the wet curing time decreases from 8 to 5 days. This indicates that decreasing the wet curing time from 8 to 5 days has little effect on the early drying shrinkage of GGBS concrete and plain cement concrete. This is mainly because the hydration of plain cement and the composite binder containing GGBS has already reached a relatively high degree (Figure 4) when the wet curing time is over 5 days, indicating that their pore structures are relatively fine and dense even when the wet curing time decreases from 8 to 5 days. However, the increments of the early drying shrinkage of GGBS concrete and plain cement concrete increased significantly, a fact that cannot be neglected when the wet curing time decreased from 5 to 2 days. (2) The increments of early and total drying shrinkage of GGBS concrete and plain cement concrete are close to each other when the wet curing time decreases from 8 to 5 days. However, the increments of early and total drying shrinkage of GGBS concrete are higher than those of plain cement concrete when the wet curing time decreases from 5 to 2 days. This indicates that the sensitivities to the change of wet curing time of drying shrinkage of these two concretes are close to each other when the wet curing time is over 5 days, whereas the sensitivity to the change of wet curing time of drying shrinkage of GGBS concrete is higher than that of plain cement concrete when the wet curing time is less than 5 days, which can be well explained by the results of the $\mathrm{w}_{n}$ content and chloride permeability. The increasing rate of the composite binder containing GGBS is much higher than that of plain cement when the wet curing time is less than 5 days. When the wet curing time is over 5 days, the hydration of the composite binder containing GGBS and plain cement reaches a relatively stable degree. Furthermore, shortening the wet curing time from 5 to 2 days does not affect the chloride permeability grade of plain cement concrete, whereas it increases the chloride permeability grade of the GGBS concrete at 360 days. (3) The increasing amplitude of the early drying shrinkage of all concretes when the wet curing time decreases from 5 to 2 days is much larger than that occurring when the wet curing time decreases from 8 to 5 days, whereas the gap is small in regard to the increment of total shrinkage. Therefore, the proportion of the early drying shrinkage to total drying shrinkage when the wet curing time decreases from 5 to 2 days is much higher than that of when the wet curing time decreases from 8 days to 5 days. This indicates that decreasing the wet curing time from 5 to 2 days has greater effects on the early drying shrinkage of concrete but limited effects on the total drying shrinkage compared to the effects of the decrease in wet curing time from 8 to 5 days. This is because the hydration degree of all binders is very low when the wet curing time is only 2 days (Figure 4 ), leading to poor pore structure, good connectivity, and thus easy transfer of moisture into the air at an early age.

3.3. Effects of Superfine Powder on Drying Shrinkage. It can be concluded from this study that the drying shrinkage of concrete with mineral admixtures increases significantly due to their low activity at an early age when the wet curing time is insufficient. This is especially the case for fly ash concrete, whose increments of early and total drying shrinkage are much larger than those of plain cement concrete due to the reduction of the wet curing time. The existing research results show that SGGBS improves reaction activity at the early and middle ages and has better resistance to capillary suction, which can decrease the drying shrinkage and improve the compactness and durability of concrete [55-59]. Therefore, replacing part of GGBS or fly ash with SGGBS (SGGBS-GGBS concrete or SGGBS-fly ash concrete) may be an effective 


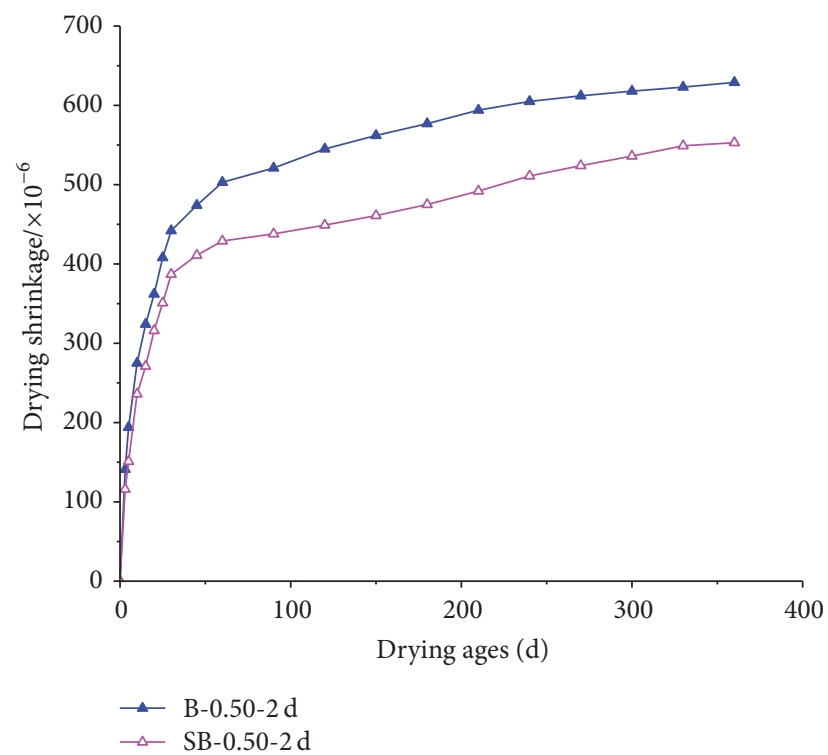

FIGURE 11: Drying shrinkage of GGBS concrete and SGGBS-GGBS concrete.

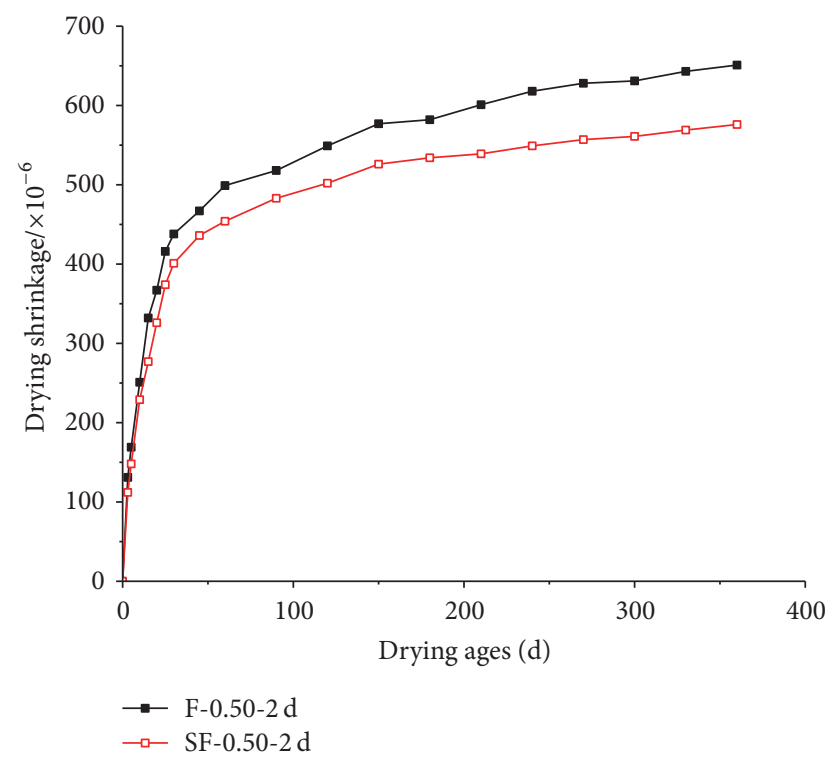

FIGURE 12: Drying shrinkage of fly ash concrete and SGGBS-fly ash concrete.

way to reduce the drying shrinkage of concrete with mineral admixtures.

Figures 11 and 12 show the drying shrinkage of GGBS concrete, SGGBS-GGBS concrete, fly ash concrete, and SGGBSfly ash concrete with W/B ratios of 0.5 after wet curing for 2 days within 1 year. It can be seen that SGGBS can reduce the drying shrinkage of GGBS concrete and fly ash concrete, which is consistent with existing research. This is mainly due to large specific surface area of SGGBS, which can increase the reaction activity and hydration process at an early age and thus improve the compactness of concrete and decrease its drying shrinkage.
It can also be seen from these two figures that with the addition of SGGBS, the decrease of the amplitude of the drying shrinkage of GGBS concrete at early and middle ages is obviously larger than that at the late age. Furthermore, SGGBS decreases the drying shrinkage of GGBS concrete much more obviously than that of fly ash concrete at early and middle ages. However, with the addition of SGGBS, the decrease of the amplitude of the drying shrinkage of fly ash concrete increases with increasing age. This indicates that SGGBS can decrease the drying shrinkage of GGBS concrete at early and middle ages significantly but has limited effects on the drying shrinkage at the late age. However, SGGBS can decrease the drying shrinkage of fly ash concrete only at the late age. Two reasons may account for it. One reason is that SGGBS can accelerate the early and middle hydration process, which is beneficial to the formation of a fine pore structure and slows down the moisture loss. However, it leads to a high proportion of pores smaller than $10 \mathrm{~nm}$ in concrete [54], which increases the drying shrinkage of concrete at a late age. The other reason is that the wet curing time is too short (only 2 days) and the replacement ratio of SGGBS is limited (only 25\%); thus, it is difficult to activate the reaction of fly ash effectively at the early and middle ages. Therefore, the formation of a fine pore structure requires a longer time.

\section{Conclusions}

The drying shrinkage of concrete within 1 year significantly increases with the decrease of wet curing time regardless of cementing components. As wet curing time is reduced, the increments of total drying shrinkage of concretes decrease with the decrease of the W/B ratio. Decreasing the wet curing time from 8 to 5 days has little effect on the increments of the early drying shrinkage of GGBS concrete and plain cement concrete. However, the increments of early drying shrinkage of GGBS concrete and plain cement concrete increased significantly when the wet curing time is reduced from 5 to 2 days. For any cementing component, decreasing the wet curing time from 5 to 2 days has greater effects on the early drying shrinkage of concrete but limited effects on the total drying shrinkage when compared to the effects of the wet curing time decreasing from 8 to 5 days.

The increasing rate of the drying shrinkage of concrete containing a mineral admixture at a late age is higher than that of plain cement concrete regardless of the wet curing time. The increasing amplitude of the drying shrinkage of fly ash concrete due to the reduction of the wet curing time is larger than that of GGBS concrete and plain cement concrete. The sensitivities to the change of wet curing time on the drying shrinkage of these two concretes are close to each other when the wet curing time is over 5 days, whereas the sensitivity to the change of the wet curing time of the drying shrinkage of GGBS concrete is higher than that of plain cement concrete when the wet curing time is less than 5 days. SGGBS can reduce the drying shrinkage of GGBS and fly ash concrete. Specifically, SGGBS can significantly decrease the drying shrinkage of GGBS concrete at the early and middle ages but has limited effects at the late age. However, SGGBS 
can decrease the drying shrinkage of fly ash concrete only at the late age.

\section{Conflicts of Interest}

The authors declare that there are no conflicts of interest regarding the publication of this paper.

\section{Acknowledgments}

Authors would like to acknowledge the Tsinghua University Initiative Scientific Research Program (20161080079).

\section{References}

[1] A. E. Idiart, C. M. López, and I. Carol, "Modeling of drying shrinkage of concrete specimens at the meso-level," Materials and Structures, vol. 44, no. 2, pp. 415-435, 2011.

[2] W. Hansen, "Drying shrinkage mechanisms in Portland cement paste," Journal of the American Ceramic Society, vol. 70, no. 5, pp. 323-328, 1987.

[3] J. Zhang, D. Hou, and Y. Gao, "Calculation of shrinkage stress in early-age concrete pavements. II: calculation of shrinkage strain," Journal of Transportation Engineering, vol. 139, no. 10, pp. 961-970, 2013.

[4] J. Zhang, D. Hou, and Y. Gao, "Integrative studies on autogenous and drying shrinkages of concrete at early-age," Advances in Structural Engineering, vol. 15, no. 7, pp. 1041-1051, 2012.

[5] C. F. Ferraris and F. H. Wittmann, "Shrinkage mechanisms of hardened cement paste," Cement and Concrete Research, vol. 17, no. 3, pp. 453-464, 1987.

[6] T. C. Powers, "The thermodynamics of volume change and creep," Matériaux et Constructions, vol. 1, no. 6, pp. 487-507, 1968.

[7] R. F. Feldman and P. J. Sereda, "Sorption of water on compacts of bottle-hydrated cement. II. thermodynamic considerations and theory of volume change," Journal of Applied Chemistry, vol. 14, no. 2, pp. 93-104, 1964.

[8] F. H. Wittmann, "Interaction of hardened cement paste and water," Journal of the American Ceramic Society, vol. 56, no. 8, pp. 409-415, 1973.

[9] R. F. Feldman and P. J. Sereda, "A model for hydrated Portland cement paste as deduced from sorption-length change and mechanical properties," Matériaux et Construction, vol. 1, no. 6, pp. 509-520, 1968.

[10] Z. P. Bažant, "Thermodynamics of hindered adsorption and its implications for hardened cement paste and concrete," Cement and Concrete Research, vol. 2, no. 1, pp. 1-16, 1972.

[11] G. Barluenga, I. Palomar, and J. Puentes, "Early age and hardened performance of cement pastes combining mineral additions," Materials and Structures/Materiaux et Constructions, vol. 46, no. 6, pp. 921-941, 2013.

[12] S. Lim, J.-H. Jeong, and D. G. Zollinger, "Moisture profiles and shrinkage in early-age concrete pavements," International Journal of Pavement Engineering, vol. 10, no. 1, pp. 29-38, 2009.

[13] T. Ayano and F. H. Wittmann, "Drying, moisture distribution, and shrinkage of cement-based materials," Materials and Structures, vol. 34, no. 247, pp. 134-140, 2002.

[14] G. W. Scherer, "Drying, shrinkage, and cracking of cementitious materials," Transport in Porous Media, vol. 110, no. 2, pp. 311-331, 2015.
[15] O. Coussy, "Chapter 4-thermoporoelasticity", in Poromechanics, pp. 71-112, John Wiley and Sons, Ltd, Chichester, UK, 2005.

[16] O. Coussy, "Chapter 9-poroviscoelasticity," in Poromechanics, pp. 261-277, John Wiley and Sons, Ltd, Chichester, UK, 2005.

[17] A. B. Eberhardt and R. J. Flatt, "Chapter 13-working mechanisms of shrinkage-reducing admixtures," in Science and Technology of Concrete Admixtures, pp. 305-320, Woodhead Publishing, Cambridge, UK, 2016.

[18] G. W. Scherer, "Theory of drying," Journal of the American Ceramic Society, vol. 73, no. 1, pp. 3-14, 1990.

[19] F. Beltzung and F. H. Wittmann, "Role of disjoining pressure in cement based materials," Cement and Concrete Research, vol. 35, no. 12, pp. 2364-2370, 2005.

[20] I. Maruyama and A. Sugie, "Numerical study on drying shrinkage of concrete affected by aggregate size," Journal of Advanced Concrete Technology, vol. 12, no. 8, pp. 279-288, 2014.

[21] G. Gelardi and R. J. Flatt, "Chapter 11-working mechanisms of water reducers and superplasticizers," in Science and Technology of Concrete Admixtures, pp. 257-278, Woodhead Publishing, Cambridge, UK, 2016.

[22] J. Saliba, E. Rozière, F. Grondin, and A. Loukili, "Influence of shrinkage-reducing admixtures on plastic and long-term shrinkage," Cement and Concrete Composites, vol. 33, no. 2, pp. 209-217, 2011.

[23] R. Siddique, "Performance characteristics of high-volume Class F fly ash concrete," Cement and Concrete Research, vol. 34, no. 3, pp. 487-493, 2004.

[24] C. S. Poon, L. Lam, and Y. L. Wong, "Study on high strength concrete prepared with large volumes of low calcium fly ash," Cement and Concrete Research, vol. 30, no. 3, pp. 447-455, 2000.

[25] V. G. Papadakis, "Effect of fly ash on Portland cement systems. part II. high-calcium fly ash," Cement and Concrete Research, vol. 30, no. 10, pp. 1647-1654, 2000.

[26] E.-H. Yang, Y. Yang, and V. C. Li, "Use of high volumes of fly ash to improve ECC mechanical properties and material greenness," ACI Materials Journal, vol. 104, no. 6, pp. 620-628, 2007.

[27] K. V. Subramaniam, R. Gromotka, S. P. Shah, K. Obla, and R. Hill, "Influence of ultrafine fly ash on the early age response and the shrinkage cracking potential of conrete," Journal of Materials in Civil Engineering, vol. 17, no. 1, pp. 45-53, 2005.

[28] J. M. Khatib, "Performance of self-compacting concrete containing fly ash," Construction and Building Materials, vol. 22, no. 9, pp. 1963-1971, 2008.

[29] Y. Akkaya, C. Ouyang, and S. P. Shah, "Effect of supplementary cementitious materials on shrinkage and crack development in concrete," Cement and Concrete Composites, vol. 29, no. 2, pp. 117-123, 2007.

[30] Y. Akkaya and M. Konsta, "The pore structure and autogenous shrinkage of high-performance concrete with ternary binders," 2004.

[31] C. Duran Atiş, C. Bilim, Ö. Çelik, and O. Karahan, "Influence of activator on the strength and drying shrinkage of alkaliactivated slag mortar," Construction and Building Materials, vol. 23, no. 1, pp. 548-555, 2009.

[32] D. W. Pfeifer, "Fly ash aggregate lightweight concrete," ACI Journal Proceedings, vol. 68, no. 3, pp. 213-216, 1971.

[33] O. Kayali, M. N. Haque, and B. Zhu, "Drying shrinkage of fibrereinforced lightweight aggregate concrete containing fly ash," Cement and Concrete Research, vol. 29, no. 11, pp. 1835-1840, 1999. 
[34] K. Sakai, H. Watanabe, M. Suzuki, and K. Hamazaki, "Properties of granulated blast-furnace slag cement concrete," in Proceedings of the Fly Ash, Silica Fume, Slag, and Natural Pozzolans in Concrete Fourth International Conference, Istanbul, Turkey, 1992.

[35] J. G. Sanjayan, T. Aly, and T. Wauer, "Long-term drying shrinkage measurements of concretes made with slag- blended cements," in Proceedings of the Concrete 05-Biennial Conference of the Concrete Institute of Australia, 2005.

[36] E. Tazawa, A. Yonekura, and S. Tanaka, "Drying shrinkage and creep of concrete containing granulated blast furnace slag," in Proceedings of the Fly Ash, Silica Fume, Slag, and Natural Pozzolans in Concrete: Proceedings of Third International Conference, pp. 1325-1343, American Concrete Institute, Trondheim, Norway, 1989.

[37] J. Yuan, W. Lindquist, D. Darwin, and J. Browning, "Effect of slag cement on drying shrinkage of concrete," ACI Materials Journal, vol. 112, no. 2, pp. 267-276, 2015.

[38] S. S. Deshpande, "Evaluating free shrinkage of concrete for control of cracking in bridge decks," SM Report No. 89 290, University of Kansas Center for Research, Inc., Kan, USA, 2007.

[39] R. D. Hooton, K. Stanish, and J. Prusinski, "The effect of ground granulated blast furnace slag (slag cement) on the drying shrinkage of concrete-a critical review of the literature," Heat \& Mass Transfer, vol. 34, no. 34, pp. 429-436, 2009.

[40] P. Wedding, F. Hogan, and J. Meusel, "Evaluation for durability and strength development of a ground granulated blast furnace slag," Cement, Concrete and Aggregates, vol. 3, no. 1, article 40, 1981.

[41] M. C. Garci Juenger and H. M. Jennings, "Examining the relationship between the microstructure of calcium silicate hydrate and drying shrinkage of cement pastes," Cement and Concrete Research, vol. 32, no. 2, pp. 289-296, 2002.

[42] J.-C. Chern and Y.-W. Chan, "Deformations of concretes made with blast-furnace slag cement and ordinary portland cement," ACI Materials Journal, vol. 86, no. 4, pp. 372-382, 1989.

[43] J. J. Brooks, Concrete and Masonry Movements, ButterworthHeinemann, Oxford, UK, 2015.

[44] A. M. Neville and J. J. Brooks, Concrete Technology, Pearson Education, NJ, USA, 2nd edition, 2010.

[45] J. Jasiczak, P. Szymański, and P. Nowotarski, "Impact of moisture conditions on early shrinkage of ordinary concrete with changing W/C ratio," Archives of Civil Engineering, vol. 60, no. 2, pp. 241-256, 2014.

[46] J. J. Brooks, "Influence of mix proportions, plasticizers and superplasticizers on creep and drying shrinkage of concrete," Magazine of Concrete Research, vol. 41, no. 148, pp. 145-153, 1989.

[47] B. Bissonnette, P. Pierre, and M. Pigeon, "Influence of key parameters on drying shrinkage of cementitious materials," Cement and Concrete Research, vol. 29, no. 10, pp. 1655-1662, 1999.

[48] E. Holt and M. Leivo, "Cracking risks associated with early age shrinkage," Cement and Concrete Composites, vol. 26, no. 5, pp. 521-530, 2004.

[49] D. P. Bentz and O. M. Jensen, "Mitigation strategies for autogenous shrinkage cracking," Cement and Concrete Composites, vol. 26, no. 6, pp. 677-685, 2004.

[50] P.-C. Aitcin, A. M. Neville, and P. Acker, "Integrated view of shrinkage deformation," Concrete International, vol. 19, no. 9, pp. 35-41, 1997.
[51] P. Aitcin, "Demystifying autogenous shrinkage," Concrete International, vol. 21, 1999.

[52] K. M. Lee, H. K. Lee, S. H. Lee, and G. Y. Kim, "Autogenous shrinkage of concrete containing granulated blast-furnace slag," Cement and Concrete Research, vol. 36, no. 7, pp. 1279-1285, 2006.

[53] A. A. Melo Neto, M. A. Cincotto, and W. Repette, "Drying and autogenous shrinkage of pastes and mortars with activated slag cement," Cement and Concrete Research, vol. 38, no. 4, pp. 565574, 2008.

[54] F. Collins and J. G. Sanjayan, "Effect of pore size distribution on drying shrinking of alkali-activated slag concrete," Cement and Concrete Research, vol. 30, no. 9, pp. 1401-1406, 2000.

[55] N. G. Lim, "The study on properties of concrete using highBlaine blast-furnace slag powder," Journal of the Korea Institute of Architecture, vol. 49, no. 10, pp. 119-129, 2005.

[56] N. G. Lim, "A foundational study on properties of high-strength concrete using nano slag by silica fume replacement," Journal of the Korea Institute of Architecture, vol. 52, no. 12, pp. 23-29, 2008.

[57] P. Sharmila and G. Dhinakaran, "Strength and durability of ultra fine slag based high strength concrete," Structural Engineering and Mechanics, vol. 55, no. 3, pp. 675-686, 2015.

[58] J. Her and N. Lim, "Physical and chemical properties of nanoslag mixed mortar," Journal of the Korea Institute of Building Construction, vol. 10, no. 6, pp. 145-154, 2010.

[59] P. Sharmila and G. Dhinakaran, "Compressive strength, porosity and sorptivity of ultra fine slag based high strength concrete," Construction and Building Materials, vol. 120, pp. 48-53, 2016. 

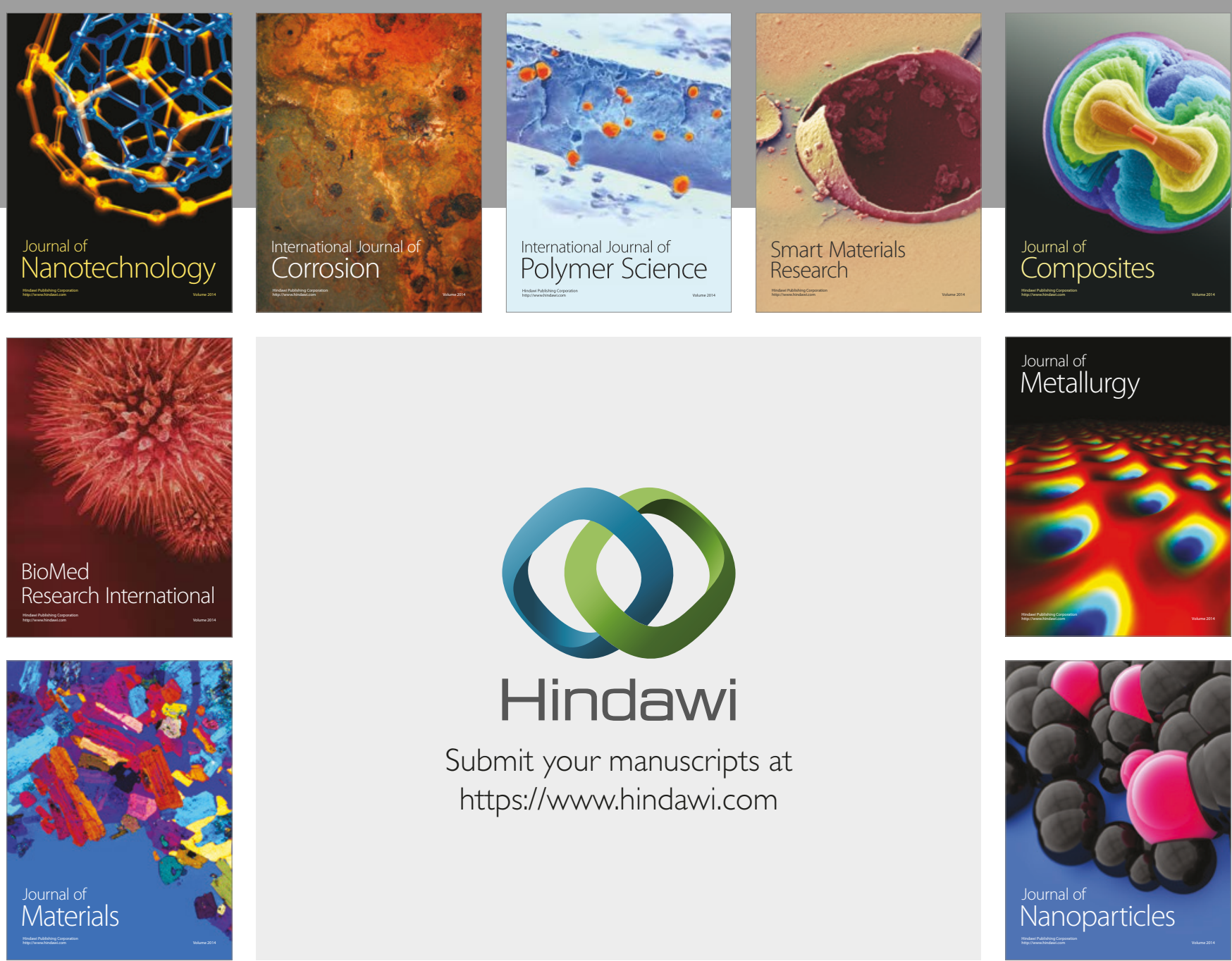

\section{Hindawi}

Submit your manuscripts at

https://www.hindawi.com
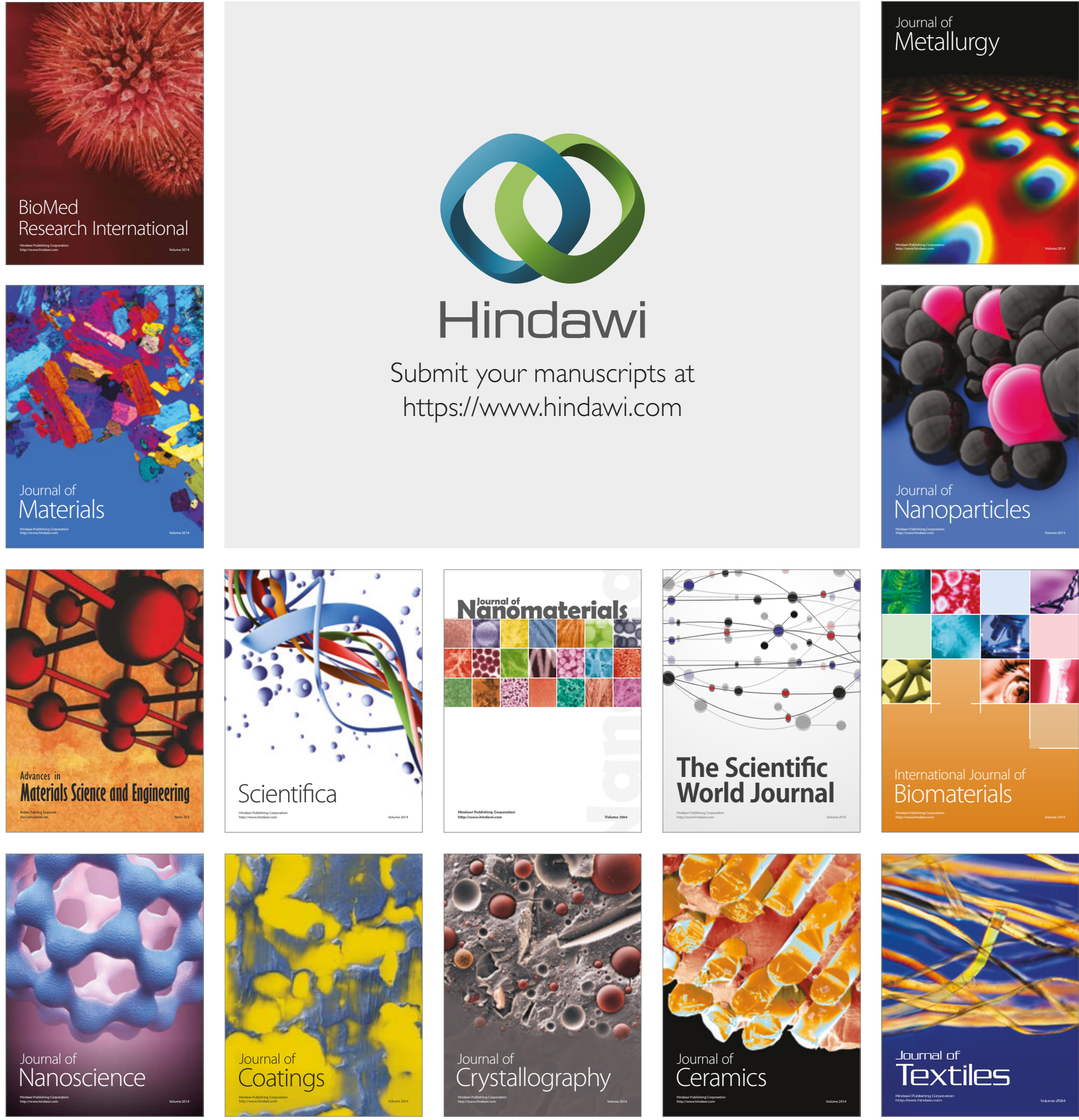

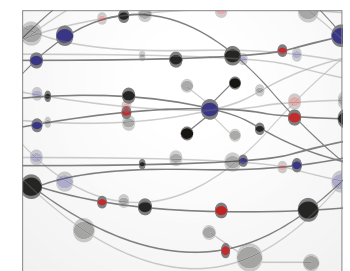

The Scientific World Journal
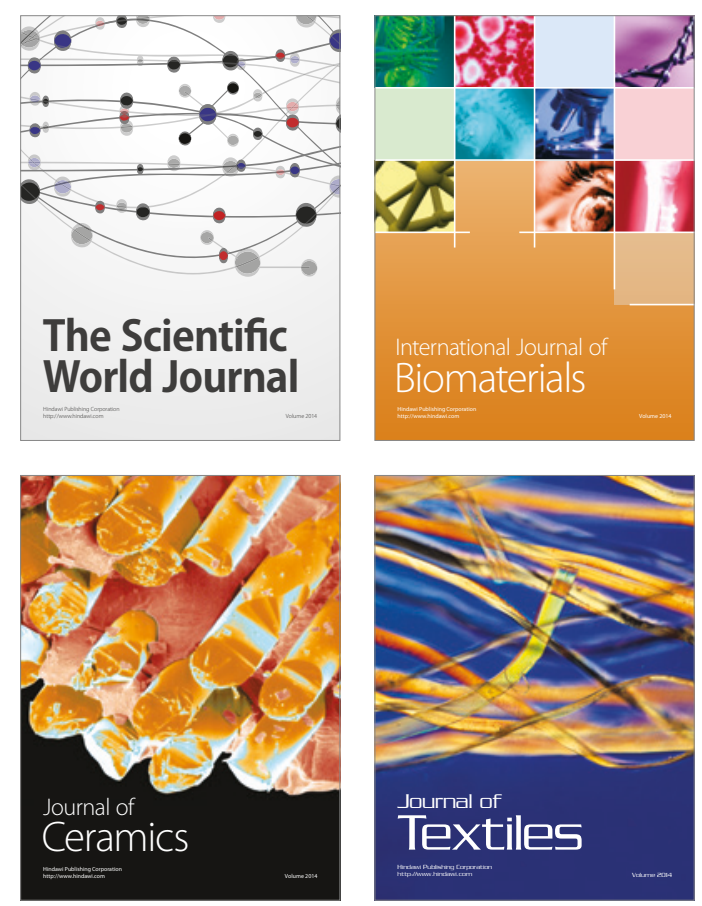